\author{
MAGDA ŻELAZOWSKA-SOBCZYK \\ Uniwersytet Warszawski \\ madziazelazowska@o2.pl \\ MAGDALENA ZABIELSKA \\ Uniwersytet im. Adama Mickiewicza w Poznaniu \\ mzabielska@wa.amu.edu.pl
}

\title{
A new variety of medical case reporting as a tool in ESP teaching as well as in medical training and professional development
}

\begin{abstract}
In this paper, a new generic development in the medical case report will be presented as a potential tool in a variety of medical contexts. A case report describes new diseases or their novel aspects, and its new interactive type additionally allows readers to comment on published cases and features patients' first person narratives. This development may be a useful tool in medical English language courses, in medical training as well as in professional development. This way the paper systematises the knowledge on the application of medical case reports in general and re-evaluates their potential in strictly medical contexts.
\end{abstract}

KEYWORDS: (interactive) case report; patient's perspective; ESP teaching; medical training; professional development.

\section{INTRODUCTION}

In this paper, a new variety of the medical case report will be discussed as a potential tool in a number of medical contexts. As a written medical genre, the case report documents "the unique, or nearly unique, case that may represent a previously undescribed syndrome or disease; the case with an unexpected association of two or more diseases or disease manifestations that may represent unsuspected causal relation; the case with an unexpected 
evolution suggesting a therapeutic effect or an adverse drug effect" (Huth 1982: 58). Its canonical structure (Rowley-Jolivet 2007) includes:

- Introduction - patient's details and presenting complaint,

- Case report body - history, physical examination/tests, diagnosis and treatment,

- Discussion/Conclusion - summary of the case as well as generalisation and implications for further diagnostic and treatment procedures.

Case reports belong to the oldest forms of communication in medicine and for a very long period of time were collected as repositories of medical knowledge. Yet, with the development of medicine, i.e., new diagnostic tools and studies based on larger populations, reported in other medical genres, case reports "f[e]ll from favour" (Vandenbroucke 2001: 333) and nowadays serve primarily pedagogical purposes in the context of medical training. However, recently, a revived interest in the genre has been observed (Nissen, Wynn 2014), resulting, for instance, in its numerous modifications, e.g., an interactive one.

The aim of this paper is to present this particular generic development and point to its potential to be a valuable tool in many medical contexts. Firstly, the new variety will be demonstrated, together with some examples. Secondly, the changes in medicine and medical practice which have contributed to the development in the variety will be discussed. Finally, the contexts in which interactive case reports may be used, will be pointed to, followed by some conclusions. Therefore, the paper aims to show the evolution of the application of this medical genre on the basis of the example of new varieties as well as to re-evaluate its potential to be used in strictly medical contexts.

\section{INTERACTIVE CASE REPORT}

As has been already observed, one of the recent developments in the genre at hand is the so-called interactive case report, whose publication was initiated by the British Medical Journal (BMJ) in 2003. In its original form, one interactive report featured actually a series of reports devoted one particular topic, appearing in consecutive issues, starting with "Case presentation", through "Case progress" to "Case outcome". The first part was similar to a regular case report presenting a given case, additionally including a call for readers' responses and comments. The progression of treatment was the topic of the second part. The third one presented outcomes of the medical management, and discussed the prognosis and implications for further investigations, including readers' comments. Apart from the introduction of 
readers' contributions supplied in the course of treatment, interactive case reports contained the patient's account, the so-called "Patient's perspective" section, which appeared in the third part. Therefore, this type of the case report consisted of smaller narratives constructed by doctors, readers and patients. It was also dynamic in that the plot developed over a series of texts. The project was eventually discontinued by the British Medical Journal due to its time-consuming character; however, it cannot be denied that it proved to be a valuable venture (Anjan K. Siotia, p. c.; cf. Pique-Angordans, Posteguillo 2006: 655; Murawska 2014).

Helán (2012) points to another group of journals publishing case reports (not interactive ones in the BMJ sense of the word) including the patient's perspective. The Journal of Medical Case Reports (JMCR) and the Cases Journal (CJ) feature occasional examples of case reports with the patient's narrative, either as a separate section ("Patient's perspective" section) or as part of the "Case presentation" section, in which the patient's words are embedded. According to the journal's guidelines, the contribution may refer but need not to be restricted to the issues such as reasons for their presentation, how symptoms developed, experience of treatment, ultimate result, etc. The editor of the Cases Journal, which ceased its publication in 2010, openly stated at the beginning that it was a journal that "wants to accept not reject and to include patients as authors as much as possible" and where "case reports can eventually be submitted by anybody - patients, doctors, nurses, relatives, anybody" (Smith 2008a: 1).

To illustrate the novelty of the variety, two excerpts will be given: (a) from one of the original interactive case reports published by the BMJ; (b) from an interactive variety which has a regular structure but retained the section and the possibility to comment on its content.

a) It was nice that I chose which symptoms were the most important to measure. This was a difficult pregnancy for me, and I was finding it difficult to cope with feeling ill and looking after my daughter. Even though the medication didn't work in the end, I don't regret doing the trial. It was helpful that someone took an interest in how I was feeling. BMJ2

b) It was a harrowing experience for me when I started balding and growing excessive hair all over my body. My fears increased as my friends and relatives started noticing a change in my voice. When the doctors told me I had a tumour, I felt my outcome was bleak. After the operation, my physical appearance improved, and my social life has returned to normal. I am grateful to the doctors for all they have done. CJ14

In the former example, while commenting on the efficacy of the management received, the patient expresses their appreciation of the interest in their perspective. In the latter, the patient focuses both on the pre- and post- 
treatment experience, giving an account of the onset of the disease and improvement after the medical procedure. Both these examples, though short, may serve as a valuable source of information regarding the patient's perceptions and expectations, which may have an impact on the overall outcome of the medical care provided.

\section{BACKGROUND FOR THE NEW DEVELOPMENT}

Bearing in mind the immense progress in medical research and practice, also the roles and activities of patients require consideration. Helán (2012) notes that it was Medicine 2.0 that contributed to the revival of the genre, and the interactive model is a good illustration of the change. By the term Medicine 2.0 is meant "applications, services and tools [which] are Web-based services for health care consumers, caregivers, patients, health professionals, and biomedical researchers, that use Web 2.0 technologies and/or semantic web and virtual-reality tools, to enable and facilitate specifically social networking, participation, apomediation, collaboration, and openness within and between these user groups" (Eysenbach 2008).

Firstly, social networking via various Internet programmes enables both patients and doctors interaction and thus sharing experience connected with illness and treatment. This, in turn, contributes to patients being more active in the processes or diagnosis and management, and, further, guarantees participation. By apomediation is meant the phenomenon when patients seek advice concerning health-related issues but not among health professionals but other apomediaries. Collaboration summarises these already mentioned elements as all of them are based on the cooperation of patients with other patients and doctors, and vice versa. Finally, openness refers to the fact that medical knowledge is becoming increasingly more frequently available to lay people or that some journals are deciding to publish openaccess material which may be then subject to readers' comments. These features can be contrasted with the characteristic features of the medicine of the pre-Internet era, i.e. text-based communication restricted to medical professionals, where patients were treated as the objects of medical procedures and recipients of treatment, and where medical knowledge very often was not free of charge and was made available only as a finished product (Greenhalgh 2001). The already mentioned interactive case reports illustrate well a more open character of contemporary medical knowledge which can be commented on by other readers, whereas the two previously mentioned journals publishing case reports - the JMCR and the $C J$ - are open access, free of charge, and additionally also subject to comments from readers. 
Therefore, it can be said that although the status of case reports (treated as subjective accounts about individual cases) has significantly decreased to the advantage of research papers (based on trials on larger populations and with the use of statistical analyses), it has been regained in the form of more available and subject to negotiation medical knowledge.

Yet another element in the background for the new variety is the paradigm of patient advocacy. A medical paradigm is a specific way of reasoning and of conceptualising things in medicine, for instance what a disease is or the role of the patient in the processes of diagnosis and treatment. The biomedical (cf. Wade, Halligan 2004) or the patient-centred (Balint et al. 1970) models can be given as examples - the first one focusing entirely on the disease and the diseased body that should be treated; the other acknowledging also the patient's experience of illness. Patient advocacy was one more step forward and was introduced to emphasise a more empowered role of the patient. Although it concerns certain aspects of health education going back to the early 1900s (Norris et al. 2008: xvii), the term advocacy has appeared in nursing literature for almost two decades (Hewitt 2002; Mallik 1997). The concept has yet to develop as a fully-fledged area of research, however it is possible to point to its main aims: "patient-centred care, safer medical systems and greater patient involvement in healthcare delivery and design" (Gilkey et al. 2008: 11). It can be referred to as "the navigator, both in its aim to help and guide patients to make well-informed decisions about their health for the best outcomes, and its quest to create more effective systems and policies" (Norris et al. 2008: xv). In other words, patient advocacy "very broadly (...) include[s] interventions targeting individual empowerment" (Gilkey et al. 2008: 13). Referring to Mattingly's (1998: 74) explanation, it is "not only what is wrong and how to fix it but also how to engage the patient in that fixing process". At the level of text, however, the model may be reflected as the involvement of the patient in a professional medical publication, which is exactly the case in interactive case reports (cf. section 2 above).

\section{SIGNIFICANCE}

In this section, the potential of the interactive variety of the report will be discussed in three contexts - ESP teaching as well as in medical training and professional development, proceeding, therefore, from a micro- to macroperspective. In this way, this examination and re-interpretation of the existing literature is aimed to show how the application of the genre of the medical case report has evolved and in what way its potential can be re-evaluated specifically in the context of medical practices. 


\subsection{ESP Teaching}

Medical case reports, also interactive ones, may be treated as a valuable tool in ESP teaching, for instance as good examples of specialised discourse, including terminology and collocations but also of structural features. With regards to the former, an important element is here collocations and phrases which are a mark of the mastery of and socialisation into professional discourse. Such linguistic elements have been identified in Helán's (2012) study of the genre at hand in general and in Zabielska's (2014) study of patient imaging in case reports in particular, as well as in a corpus-based study of biomedical English in scientific writing by Salazar and colleagues (2013). The first two studies point to collocations and phrases characteristic of particular types of information appearing in specific parts of the case report, for instance a patient's presenting complaint (Introduction), cf. (c) and (d) below (Zabielska 2014); history, physical examination/tests, diagnosis and treatment (Case report body), cf. (e) (Zabielska 2014), (f) and (g) (Helán 2012), and (h) (Zabielska 2014) respectively; and the discussion of the case (Discussion/Conclusion), cf. (i) (Zabielska 2014) and (j) (Salazar et al. 2013).

c) patient presented to medical institution with symptoms A 64-year-old woman presented to the emergency department with a stiff painful jaw. LA14

d) patient complained about symptoms

She had complained of worsening holocephalic headache. LA14

e) patient's history was

His medical history was negative for underlying illnesses. JA2 (Zabielska 2014)

f) on/upon examination, on/upon admission

On examination, the 14-month-old patient was found to be afebrile and tachypneic... JMCR 3/1/6495

On abdominal examination, there was no tenderness or palpable masses. JMCR 2/1/384

On clinical examination his right thumb was swollen and tender... CJ $2 / 1 / 8304$

g) diagnosis was made

A clinical diagnosis of left hamstring tendinitis was made. JMCR 4/1/76 (Helán 2012)

h) patient was treated

The patient was treated with ketoconazole alone and then in combination with the glucocorticoid antagonist mifepristone, but the drugs did not control the hypercortisolism. NEJM10 (Zabielska 2014) 
i) disease diagnosed in patient

In 1994, splenomegaly was documented in a 72-year-old woman from the Greek island of Karpathos during a routine examination (her first in many years). NEJM2 (Zabielska 2014)

j) in this case/in the present case

In the present case in which SAC6 is overexpressed, these bars likely reflect an increase in actin filament cross-linking activity. G5 (Salazar et al. 2013)

Additionally, Mungra and Canziani (2013) offer a wordlist for clinical medicine compiled by means of a quantitative analysis of the lexis of clinical case histories, which, though not referring to particular text sections, may also prove helpful in ESP teaching. Garzone (2011: 119) draws attention also to case records (part of hospital documentation of patients' diagnosis and treatment) as "articulate piece[s] of authentic discourse, where complex technical notions are expressed in highly technical language". These pieces are particularly useful with their evaluative expressions for medical conditions necessary for precise assessment.

\subsection{Medical training}

Case reports perform a very important function also in the process of socialisation into medical practice. A case is "the basic unit of medical thought" (Hunter 1991: 51) and, as Smith (2008b: 1) puts it, "every new condition - whether it is AIDS, SARS, or the next emergent disease - begins with a single case". Communication in medicine revolves around cases and many medical genres, both spoken and written, are case-based, i.e. case presentations, case records, etc. Therefore, from the very beginning, medical students are socialised into thinking in terms of cases, for instance when they discuss patients' cases during hospital ward rounds, recounting details of a presenting complaint, a review of systems, their possible assessment and proposed treatment. During this activity, young adepts of medicine learn not only what information is relevant in such a presentation, but also in what sequence it should be given and what linguistic means should be used. This way, medical students acquire the ability to work up a case. This can and often is practiced on the basis of case reports (cf. Pettinari 1988; Charon 2001; Kenny, Beagan 2004).

In particular, first, case reports may be used to acquaint young doctors with the so-called diagnostic thought - i.e., examining particular cases and drawing on the available knowledge. "Through this attempt, authors learn to perform a focused literature search, explain history, demonstrate analytical skills, [and to] provide rational explanations for the findings" 
(Bavdekar, Save 2015: 45; cf. Morgan 1985). Second, they can be helpful in grasping the concept of the whole body and its functioning, and how it is related to the origins to particular diseases (Engelberg 1992; cf. Mungra, Canziani 2013: 41; Bavdekar, Save 2015). In this context, Engelberg (1992) gives an example of reports from clinicopathological conferences from the NEJM. For first-year medical and graduate students, they are a useful tool in acquiring the process of working up a case, drawing on their knowledge gained in the previous years. Also many clinical events where medical issues are referred to particular cases in order to show the applicability of presented knowledge or research (Wall 2008: 235-236, cf. Garzone 2011: 125 for this issue in the context of case records). This, in turn, is a reflection of the revival a teaching methodology called Problem-Based Learning (PBL) (Barrows 1990; Frederiksen 1999), where the teaching process is contextualised in a particular situation, as it offers clinicians "better insight into the unusual riddles which specialists usually encounter in their everyday practice" (Yitschaky et al. 2011: 180). In sum, "[a] good case report begets awareness, jogs the memory and adds to understanding" (Morgan 1985: 353).

\subsection{Professional development}

The editors of the original interactive case reports emphasised the innovative nature of the format, which, at the same time, was challenging both for doctors and patients, as it presented new perspectives in medical practice. The value of the "Patient's perspective" section in interactive case reports in general can be twofold. On the one hand, the fact that it appears in a professional medical publication emphasises the importance of the patient's account with it being a potential source of information. In detail, these are "personal vignettes (e.g., exploring the dynamics of the patientphysician relationship) taken from wide-ranging experiences in medicine" (JAMA Instruction for authors 1), offering "lesson[s] applicable to caring, humanism, and relationship in health care" (Hatem, Rider 2004: 252). What is more, the fact that the patient has the opportunity to share their story of illness may have a therapeutic effect (Haidet, Paterniti 2003; cf. Frank 1995; Borkan et al. 2001; Sharf, Vanderford 2003). With regards to doctors, patients' stories allow doctors to reflect on their practice (Davidoff 1996: 270), “(...) emphasis[ing] the importance of reflection in [their] learning and how [their] patient and self-care can be improved through regular practice, similar to other health provider skills" (Hatem, Rider 2004: 252). This way, authors engaged in the variety go beyond the textual acknowledgement of the 
patient's experience and invite the patient to co-produce the account, which might be seen as a textual reflection of the paradigm of patient advocacy (Smith 2006; cf. Earp et al. 2008, cf. section 3 above).

\section{CONCLUSION}

The aim of this paper was to present a new generic development in the medical case report as a potential tool in ESP teaching as well as in medical training and professional development. A case report describes new diseases or diseases which are already known but which have unusual manifestations. Recently, a new variety of the genre, i.e., an interactive case report, has appeared, which reflects broader changes in medical practice. These changes are patient's advocacy, a paradigm which emphasises the empowerment of the patient in the processes of diagnosis and treatment in general, and apomediation, collaboration and Medicine 2.0 in detail, which point to numerous patients' activities aimed at seeking advice and support, not infrequently by means of web-based tools. In the paper, after a brief description of the canonical case report, its new variety was discussed, which allows readers to comment on published cases and features first person narratives by the patient. The article also pointed to the potential of this publication type to be a useful tool in a variety of contexts: medical English language courses, especially in terms of terminology and frequently used expressions, medical training, exemplifying a typical way of reasoning of working up a case, as well as in professional development, through acknowledging the patient's contribution and emphasising reflection on the part of the doctor. In this way, the paper systematises the knowledge on the application of medical case reports as well as reinterprets their potential in particular medical practices. More specifically, the paper demonstrates the evolution of the use of this medical genre in general on the basis of its new varieties, but it also shows that the practices in which case reports are used in the medical context are of communicative nature too.

\section{REFERENCES}

Arioglu, E., Doppman, J., Gomes, M., Kleiner, D., Mauro, D., Barlow, C., Papanicolaou, D.A. 1998. Cushing's Syndrome Caused by Corticotropin Secretions by Pulmonary Tumorlets. In: New England Journal of Medicine 339/13, 883-886. http://content.nejm.org/cgi/reprint/ 339/13/883.pdf (date of access: 01.01.2008). NEJM10

Balint, M., Hunt, J., Joyce, D., Marinker, M., Woodcock, J. 1970. Treatment or Diagnosis: A Study of Repeat Prescriptions in General Practice. London: Tavistock. 
Barrows, H.S. 1990. The Pedagogical Importance of a Skill Central to Clinical Practice. In: Medical Education 24/1, 3-5.

Bavdekar, S.B., Save, S. 2015. Writing Case Reports: Contributing to Practice and Research. In: Journal of The Association of Physicians of India 63, 44-48.

Borkan, J., Reis, S., Medalie, J. 2001. Narratives in Family Medicine: Tales of Transformation, Points of Breakthrough for Family Physicians. In: Families, Systems \& Health 19/2, 121-134.

Charon, R. 2001. Narrative Medicine. A Model for Empathy, Reflection, Profession, and Trust. In: Journal of American Medical Association 286/15, 1897-1902.

Davidoff, F. 1996. On Being a Patient. In: Annals of Internal Medicine 124/2, 269-270.

Douglas, R.J. 2010. Palpitations Following Regular Ibuprofen Dosing in a 13-year-old Girl: A Case Report. In: Journal of Medical Case Reports 4/76. http://www.jmedicalcasereports. com/content/4/1/76 (date of access: 01.01.2011). JMCR 4/1/76

Earp, J.-A. L., French, E.A., Gilkey, M.B. (eds). 2008. Patient Advocacy for Health Care Quality: Strategies for Achieving Patient-centred Care. Boston: Jones and Bartlett Publishers.

Engelberg, J. 1992. Complex Medical Case Histories as Portals to Medical Practice and Integrative, Scientific Thought. In: American Journal of Physiology 263/6, 45-54.

Eysenbach, G. 2008. Medicine 2.0: Social Networking, Collaboration, Participation, Apomediation, and Openness. In: Journal of Medical Internet Research 10/3. http://dx.doi.org/ 10.2196/jmir.1030 (date of access: 01.01.2009).

Frank, A. 1995. The Wounded Storyteller: Body, Illness, and Ethics. Chicago: The University of Chicago Press.

Frederiksen, C. 1999. Learning to Reason through Discourse in a Problem-based Learning Group. In: Discourse Processes 27/2, 135-160.

Garzone, G. 2011. Rethinking Genres in Medical Communication: Theoretical Issues and Pedagogical Implications. In: Loiacono, A., Iamartino, G., Grego, K.S. (eds). Teaching Medical English. Methods and Models. Milano: Polimetrica, 105-131.

Gilkey, M.B., Earp, J.-A.L., French, E.A. 2008. What is Patient Advocacy? In: Earp, J.-A.L., French, E.A., Gilkey, M.B. (eds). Patient Advocacy for Health Care Quality: Strategies for Achieving Patient- centred Care. Boston: Jones and Bartlett Publishers, 3-28.

Greenhalgh, T. 2001. How to Read a Paper. The Basics of Evidence Based Medicine. London: BMJ Books.

Haidet, P., Paterniti, D. 2003. Building a History rather than Taking One. A Perspective on Information Sharing during the Medical Interview. In: Archives of Internal Medicine 163/10, 1134-1140.

Harker, N., Montgomery, A., Hafey, T. 2004. Treating Nausea and Vomiting during Pregnancy: Case Outcome. In: British Medical Journal 328, 503. http://dx.doi.org/10.1136/bmj. 328.7438.503 (date of access: 01.02.2010). BMJ2

Hatem, D., Rider, E.A. 2004. Sharing Stories: Narrative Medicine in an Evidence-based World. In: Patient Education and Counselling 54/3, 251-253.

Helán, R. 2012. Analysis of Published Medical Case Reports: Genre-based Study. Unpublished PhD dissertation. Brno: Masaryk University. https://is.muni.cz/th/18899/ff_d/DISSERTA TION_-_ROBERT_HELAN.pdf (date of access: 23.07.2012).

Hewitt, J. 2002. A Critical Review of the Arguments Debating the Role of the Nurse Advocate. In: Journal of Advanced Nursing 37/5, 439-445.

Hunter, K.M. 1991. Doctors' Stories. The Narrative Structure of Medical Knowledge. Princeton: Princeton University Press.

Huth, E.J. 1982. How to Write and Publish Papers in the Medical Sciences. Philadelphia: Institute for Scientific Information Press. 
JAMA Instruction for Authors 1.

http://jama.jamanetwork.com/public/instructionsForAuthors.aspx\#CategoriesofArticles (date of access: 01.06.2014).

Kenny, N.P., Beagan, B.L. 2004. The Patient as Text - a Challenge for Problem-based Learning. In: Medical Education 38/10, 1071-1079.

Lees, A.N., Reid, D.W. 2008. Management Dilemma; A Woman with Cystic Fibrosis and Severe Lung Disease Presenting with Colonic Carcinoma: A Case Report. In: Journal of Medical Case Reports 2/384. http://www.jmedicalcasereports.com/content/2/1/384 (date of access: 01.01.2011). JMCR 2/1/384

Lindley-Jones, M., Lewis, D., Southgate, J.L. 2004. Recurrent Tetanus. In: Lancet 363, 2048. http://150.254.100.169/han/TheLancet/vls1.icm.edu.pl/pdflinks/09092612044900452.pdf (date of access: 04.08.2007). LA14

Mak, R., Gray, G.C., Malasig, M.D., Binn, L.N., Asher, L.V., Cute, D., Kehl, S.C., Dunn, B.E., Zablocki, J., Yund, A.J. 2001. Two Fatal Cases of Adenovirus-related Illness in Previously Healthy Young Adults - Illinois, 2000. In: Journal of American Medical Association 286/7, 553-556. http://jama.ama-assn.org/cgi/content/full/286/7/782 (date of access: 18.05.2008). JA2

Mallik, M. 1997. Advocacy in Nursing: A Review of the Literature. In: Journal of Advanced Nursing 25/1, 130- 138.

Mattingly, C. 1998. Healing Dramas and Clinical Plots. The Narrative Structure of Experience. Cambridge: Cambridge University Press.

Morgan, P.P. 1985. Why Case Reports? In: CMAJ 133/5, 353.

Mungra, P., Canziani, T. 2013. Lexicographic Studies in Medicine: Academic Word List for Clinical Case Histories. In: Ibérica 25, 39-62.

Murawska, M. 2014. Interactive Case Reports - a Case in Point. In: Lankiewicz, H., Wąsikiewicz-Firlej, E. (eds). Languaging Experiences: Learning and Teaching Revisited. Newcastle upon Tyne: Cambridge Scholars Publishing, 95-115.

Nissen, T., Wynn, R. 2014. The Clinical Case Report: A Review of its Merits and Limitations. In: BMC Research Notes 7/264. http:/ / www.biomedcentral.com/1756-0500/7/264 (date of access: 01.02.2015).

Norris, A., Norris, L., Pearson, C. 2008. Preface. In: Earp, J.-A.L., French, E.A., Gilkey, M.B. (eds). Patient Advocacy for Health Care Quality: Strategies for Achieving Patient-centred Care. Boston: Jones and Bartlett Publishers, $\mathrm{xv}-\mathrm{xx}$.

Pettinari, C.J. 1988. Task, Talk, and Text in the Operating Room: A Study in Medical Discourse. Norwood: Ablex Publishing Company.

Pique-Angordans, J., Posteguillo, S. 2006. Medical Discourse and Academic Genres. In: Brown, K. (ed.). Encyclopaedia of Language and Linguistics. Amsterdam: Elsevier, 649-657.

Ramoutar, D.N., Katevu, C., Titchener, A.G., Patel, A. 2009. Trapezium Fracture - a Common Technique to Fix a Rare Injury: A Case Report. In: Cases Journal 2/8304. http://www.casesjournal.com/content/2/1/8304 (date of access: 01.01.2011). CJ 2/1/8304

Rowley-Jolivet, E. 2007. A Genre Study of if in Medical Discourse. In: Fløttum, K. (ed.). Language and Discipline Perspectives on Academic Discourse. Newcastle: Cambridge Scholars Publishing, 184-214.

Salazar, D., Verdaguer, I., Laso, N.J., Comelles, E., Castano, E., Hilferty, J. 2013. Formal and Functional Variation of Lexical Bundles in Biomedical English. In: Verdaguer, I., Laso, N.J., Salazar, D. (eds). Biomedical English. A Corpus-based Approach. Amsterdam: John Benjamins, 39-53. 
Salim, S., Palamaner Subash Shantha, G., Patel, A.D., Kumar, A.A., Ganeshram, P., Mehra, N., Rajan, A.G., Joseph, T., Sudhakar, L. 2009. Virilising Ovarian Steroid Cell Tumour in a 40 Year Old South Indian Female: A Case Report. In: Cases Journal 2/7521. http:/ / casesjournal. com/casesjournal/article/view/7521 (date of access: 03.09.2012). CJ14

Sandrock, T.M., Brower, S.M., Toenjes, K.A., Adams, A.E. 1995. Suppressor Analysis of Fimbrin (Sac6p) Overexpression in Yeast. In: Genetics 151/4, 1287-1297. G5

Sharf, B.F., Vanderford, M.L. 2003. Illness Narratives and the Social Construction of Health. In: Dorsey, A., Miller, K.I., Parrott, R., Thompson, T. (eds). The Handbook of Health Communication. Mahwah NJ: Lawrence Erlbaum Associates, 9-34.

Smith, J.C., Cohen, E. 2009. Beta-2-Transferrin to Detect Cerebrospinal Fluid Pleural Effusion: A Case Report. In: Journal of Medical Case Reports 3/6495. http://www.jmedicalcasereports. com/content/3/1/6495 (date of access: 01.01.2011). JMCR 3/1/6495

Smith, R. 2008a. The Policies of Cases Journal. In: Cases Journal 1/2. http:/ /www.casesjournal. com/content/1/1/2 (date of access: 01.02.2013).

Smith, R. 2008b. Why Do We Need Cases Journal. In: Cases Journal 1/1. http://www. casesjournal.com/content/1/1/1 (date of access: 17.07.2013).

Smith, T. 2006. Changing Relationships between People and Providers: Making Sense of Patient-centred Health Care. In: Quality and Safety in Health Care 15/1, 71-73.

Vandenbroucke, J. P. 2001. In Defence of Case Reports and Case Series. In: Annals of Internal Medicine 134/4, 330-334.

Vinetz, J.M., Li, J., McCutchan, T.F., Kaslow, D.C. 1998. Plasmodium Malariae Infection in an Asymptomatic 74-year-old Greek Woman with Splenomegaly. In: New England Journal of Medicine 338/6, 367-371. http://content.nejm.org/cgi/reprint/338/6/367.pdf (date of access: 18.05.2008). NEJM2

Wade, D.T., Halligan, P.W. 2004. Do Biomedical Models of Illness Make for Good Healthcare Systems? In: British Medical Journal 329, 1398-1401.

Wall, E.E. van der 2008. Case History: More than a Beauty Case! A Case for Case Histories. In: Netherlands Heart Journal 16/7/8, 235-236.

Yitschaky, O., Yitschaky, M., Zadik, Y. 2011. Case Report on Trial: Do You, Doctor, Swear to Tell the Truth, the Whole Truth and Nothing but the Truth? In: Journal of Medical Case Reports 5/179. http://www.jmedicalcasereports.com/content/pdf/1752-1947-5-179.pdf (date of access: 01.06.2015).

Zabielska, M. 2014. Searching for the Patient's Presence in Medical Case Reports. Frankfurt a. Main: Peter Lang. 